\title{
CARDIFRC $^{\circledR}-$ Development and mechanical properties. Part III: Uniaxial tensile response and other mechanical properties
}

\author{
S. D. P. Benson*, $\dagger$ and B. L. Karihaloo* \\ Cardiff University
}

Part III of this three-part paper about CARDIFRC ${ }^{\circledR}$, a class of high performance short steel fibre-reinforced cementitious composites (HPFRCCs), deals with the measurement of the tensile response of CARDIFRC ${ }^{\mathbb{R}}$ mixes on a specially developed specimen geometry and loading arrangement. It also compares the measured mechanical properties (Young's modulus, $E$, compressive strength, $f_{\mathrm{c}}$, tensile strength, $f_{\mathrm{t}}$, specific fracture energy, $G_{\mathrm{F}}$ ) with the theoretically predicted values using micromechanical relations.

\section{Notation}

F coefficient of friction between matrix and fibre

$g \quad$ maximum size of coarse aggregate

$K_{\text {Ic,m }} \quad$ matrix fracture toughness

$K_{\mathrm{Ic}, \mathrm{p}} \quad$ binder fracture toughness

$s p / w \quad$ superplasticiser to water ratio

$V_{\mathrm{a}} \quad$ aggregate volume fraction

$w / b \quad$ water to binder ratio

$\sigma \quad$ stress

$\varepsilon \quad$ strain

$w \quad$ crack mouth opening

\section{Introduction}

Part III of this three-part paper reports on the investigations undertaken to establish the complete tensile load-deformation response of CARDIFRC ${ }^{\mathrm{R}}$, a class of high performance short steel fibre-reinforced cementitious composites (HPFRCCs). It also reports on how the measured mechanical properties (Young's modulus, $E$, tensile strength, $f_{\mathrm{t}}$, specific fracture energy, $G_{\mathrm{F}}$

* School of Engineering, Queen's Buildings, Newport Road, PO Box 925, Cardiff, CF24 OYF, UK.

$\dagger$ Present address: Parsons Brinckerhoff, 29 Cathedral Road, Cardiff CF11 9HA, UK.

(MCR 41272) Paper received 22 April 2004; last revised 14 October 2004; accepted 1 February 2005 and compressive strength, $f_{\mathrm{c}}$ ) for the two types of CARDIFRC $^{\circledR}$ mix compare with the predictions of theoretical models.

Tension tests are very sensitive to the loading arrangement, ${ }^{1}$ which often results in premature failure of the test specimen near the grips due to stress concentrations. In order to avoid such a situation, research was undertaken to develop a tension specimen and test arrangement that would ensure a uniform tensile stress field over a large area that is unaffected by the loading arrangement. The novel test specimen and loading arrangement are described below, together with the complete tensile load-deformation response of the mix. This consists of a linear-elastic region, followed by a pre-peak strain-hardening region and finally an extensive post-peak tension softening region.

The assumptions made in the existing micromechanical relations are presented to enable a more accurate prediction of the mechanical properties of CARDIFRC ${ }^{\circledR}$ mixes. Then the measured mechanical properties will be compared with their theoretically predicted values.

\section{Tensile response}

High-performance fibre-reinforced cementitious composites, such as CARDIFRC ${ }^{\circledR}$ have been shown ${ }^{2-8}$ to exhibit a linear elastic behaviour, followed by an extensive strain-hardening response up to the peak load and a tension softening response thereafter. The strain hardening behaviour of this mixture is believed to be 
due to the nucleation of microcracks under increasing tensile/flexural stress. ${ }^{2,3}$ In the literature, assumptions have been made on their evolution but no experimental evidence is available to validate them. An experimental programme was therefore implemented to describe the complete tensile load-deformation response of CARDIFRC $^{\mathbb{R}}$

The uniaxial tension test is a very sensitive and difficult test to perform. ${ }^{1}$ Common problems include the misalignment of the specimen both before and during the test, the gripping arrangement and specimen shape (i.e. ensuring that the failure occurs far enough away from the grips), and defects in the specimens (such as large pores or poor fibre distribution) which lead to stress concentrations. Another important factor is the controlling gauge length. If the gauge length is too large snap-back behaviour can occur when the stored elastic energy is released from the material outside of the fracture process zone and if the gauge length is too short it may not be possible to control the test if the fracture process zone occurs outside of the controlling gauge length. These factors will now be discussed.

\section{Specimen shape}

The most common specimen shapes used for uniaxial tension testing are cylinders, prisms and dog-bones, both notched and unnotched. A common problem for the unnotched cylinders and prisms is that when the steel loading platens are bonded on to the specimen stress concentrations occur due to the mismatch between the Young modulus and Poisson's ratio of the concrete and steel. These stress concentrations often lead to so-called 'bond failure' in which the concrete layer close to the glue fails. ${ }^{9}$ It is common practice to use notched specimens to avoid the difficulties of bond failure and to force the crack to appear in a known region thus simplifying crack observation. However, as the microcracks will form in a small area around the notch, it will not be possible to observe crack evolution and propagation, since due to the stress concentration a through crack will form at the notch and cracking will not occur elsewhere in the specimen.

When the cross-section towards the ends of the specimens is increased (like that of a dog-bone) the boundary stresses will be reduced and the bond failure is generally avoided. The failure should occur in the prismatic part of the specimen where, in theory, the shape effects are absent. ${ }^{9}$ Crack initiation in the straight part of the specimen (Fig. 1(a)) can only be obtained when the stress concentrations at the end of the curved edge are overruled by the heterogeneity of the concrete, in other words the crack will occur at the weakest point. ${ }^{9}$ It is therefore desirable to remove the straight section and to have a continuous transition curve (Fig. 1(b)). To ensure a specimen geometry with a uniform tensile stress field over a large area that is unaffected by the loading arrangement, Neuber's solution ${ }^{10}$ was adopted.

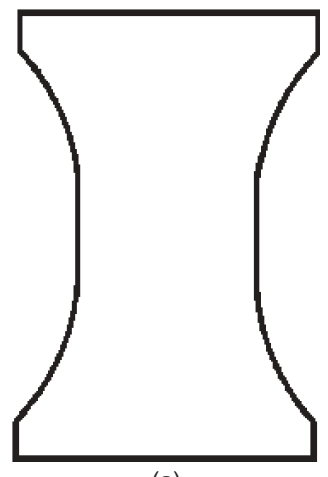

(a)

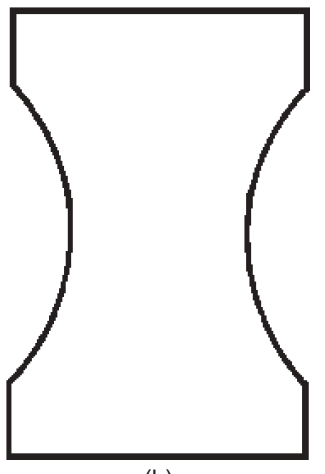

(b)
Fig. 1. Typical dog-bone shaped specimens (After Ref. 9)

The specimen shown in Fig. 2 ensures a central area in which the tensile stress is uniform and well defined. Neuber's solution ${ }^{10}$ ensures no stress concentration along the continuous transition curve (Fig. 3). To define the transition curve a precise spline fit is calculated as follows

Choose the length of the transition zone, i.e. $\left(x_{2}-x_{1}\right)$ (see Fig. 3)

Prescribe $y_{1}$ and $y_{2}$.

Solve for $c$ the equation

$$
c \frac{\pi}{2}+\left(y_{1}-c \frac{\pi}{2}\right) \mathrm{e}^{\left(x_{2}-x_{1}\right) / c}=y_{2}
$$

Calculate

$$
\lambda=\frac{y_{1}}{c}-\frac{\pi}{2}
$$

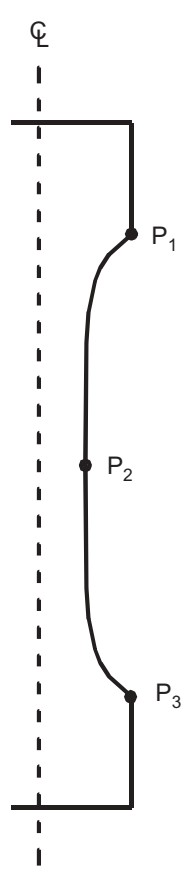

Fig. 2. Neuber's curve used to design a tension specimen with a large area of uniform stress

Magazine of Concrete Research, 2005, 57, No. 8 


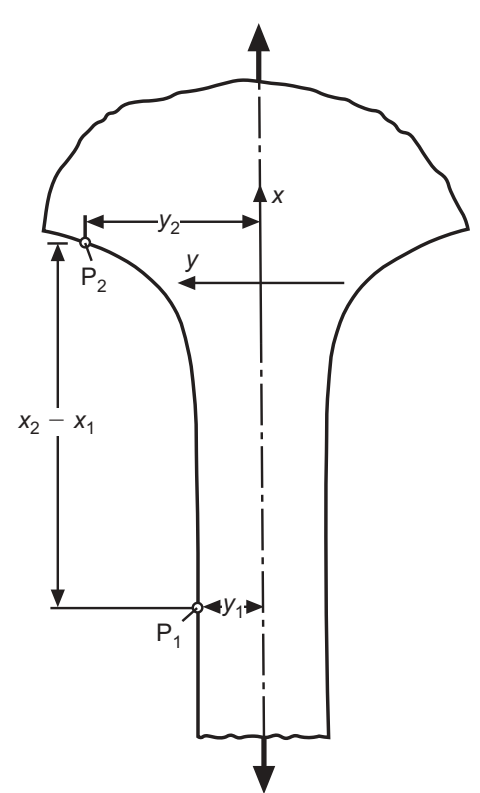

Fig. 3. Geometry of transition spline to eliminate stress concentrations

and

$$
x_{1}=c \ln \lambda
$$

Calculate $x_{2}$.

The remaining points between $x_{2}$ and $x_{1}$ are given by

$$
y=c\left(\frac{\pi}{2}+\mathrm{e}^{\frac{x}{c}}\right)
$$

Using these formulae, the coordinates for the spline of the tension specimen (Fig. 2) were determined using a transition zone length $\left(\mathrm{P}_{1}\right.$ to $\mathrm{P}_{2}$ or $\mathrm{P}_{3}$ to $\left.\mathrm{P}_{2}\right)$ of $250 \mathrm{~mm}, y_{1}=50 \mathrm{~mm}$ and $y_{2}=100 \mathrm{~mm}$.

From equation (1) $c=31 \cdot 82$, equation (2) gives $\lambda=0.000609$ and equation (3) gives $x_{1}=-235.61 \mathrm{~mm}$ and $x_{2}=14.40 \mathrm{~mm}$.

The coordinates of the spline between $\mathrm{P}_{1}$ and $\mathrm{P}_{2}$ were determined using

$$
y=\left[c\left(\frac{\pi}{2}+\mathrm{e}^{\left(\frac{x-x_{1}}{c}\right)}\right)\right]-50
$$

The coordinates of the spline between $\mathrm{P}_{3}$ and $\mathrm{P}_{2}$ were determined using

$$
y=\left[c\left(\frac{\pi}{2}+\mathrm{e}^{\left(\frac{-x-x_{1}}{c}\right)}\right)\right]-50
$$

The Neuber specimen (a shape which has not been previously used for uniaxial tension testing) is an elongated dog-bone type shape with an overall length of $740 \mathrm{~mm}$ (500 mm of which is the transition spline), a width of $100 \mathrm{~mm}$ at the centre of the specimen which increases gradually to $200 \mathrm{~mm}$ at the end of the transition spline and a thickness of $35 \mathrm{~mm}$ (Fig. 4).

Prior to casting specimens with this transition spline shape, a commercial finite element analysis (FEA) package, LUSAS, was used to check the uniformity of the stress along the spline. Fig. 5(a) shows the finite element mesh of quadrilateral elements for plane stress analysis. The Young's modulus and Poisson's ratio were assumed to be $40 \mathrm{GPa}$ and $0 \cdot 2$, respectively. Fig. 5(b) shows a contour plot of the axial stress $\sigma_{y y}$. It is found that the area of uniform stress is too large for observing cracks with a charge coupled device (CCD) camera coupled with a high magnification optical lens because this would demand a very high scanning rate to cover such a large area. So, to aid observation of crack evolution during testing, FEA was again used to develop a modified spline that would ensure a smaller central area of uniform stress. The Neuber spline was modified by gradually moving some of the points of the spline. After each adjustment the analysis was re-run and a contour plot of the stress $\sigma_{y y}$ produced to determine any improvement. This iterative process was repeated approximately forty times until the maximum stress contour moved towards the centre of the specimen creating a smaller central region of uniform stress (Fig. 6). The length of the modified Neuber transition spline is identical to that of the Neuber spline, but the horizontal coordinates of the spline are slightly different (see Fig. 7). The length of the transition zone is vital to ensuring an area of constant normal stress. If this length is reduced stress concentrations will appear in the zone of observation of microcracks.

\section{Gripping arrangement}

The gripping arrangement of a tensile specimen can be fixed or rotating. As fixed grips prevent the ends of the specimens from rotating, a crack can initiate at one edge of the specimen resulting in an eccentric loading which is then counteracted by a bending moment. This enables another crack to form on the opposite edge. Evidence of this can be seen in the stress/crack-opening graph in the form of a post-peak plateau in the recorded load-elongation curve. ${ }^{1}$ In the rotating grips, the specimen ends are free to rotate during the test. A crack initiates on one edge and no counteracting bending moment will occur, resulting in crack propagation from one side of the specimen towards the other. The use of rotating grips produces the lowest values for fracture energy and tensile strength, implying that the rotating boundary conditions have a lesser influence on the test results. The reason for this is believed to be that failure is able to occur in the weakest area in the specimen. However the deformations are highly nonuniform and the scatter of results is larger for rotating boundary conditions. ${ }^{9}$ Cattaneo and Rosati ${ }^{11}$ also reported that rotating platens resulted in lower peak stress (strength) and fracture energy values. Rotating grips were chosen for the Neuber and modified Neuber specimens to obtain lower bounds on tensile strength and fracture energy. The bonded and pinned plates shown in Fig. 4(c) and Fig. 8 were purpose designed and fabricated to achieve the effect of rotating grips. A pair of plates were bonded on each end of the specimen. 


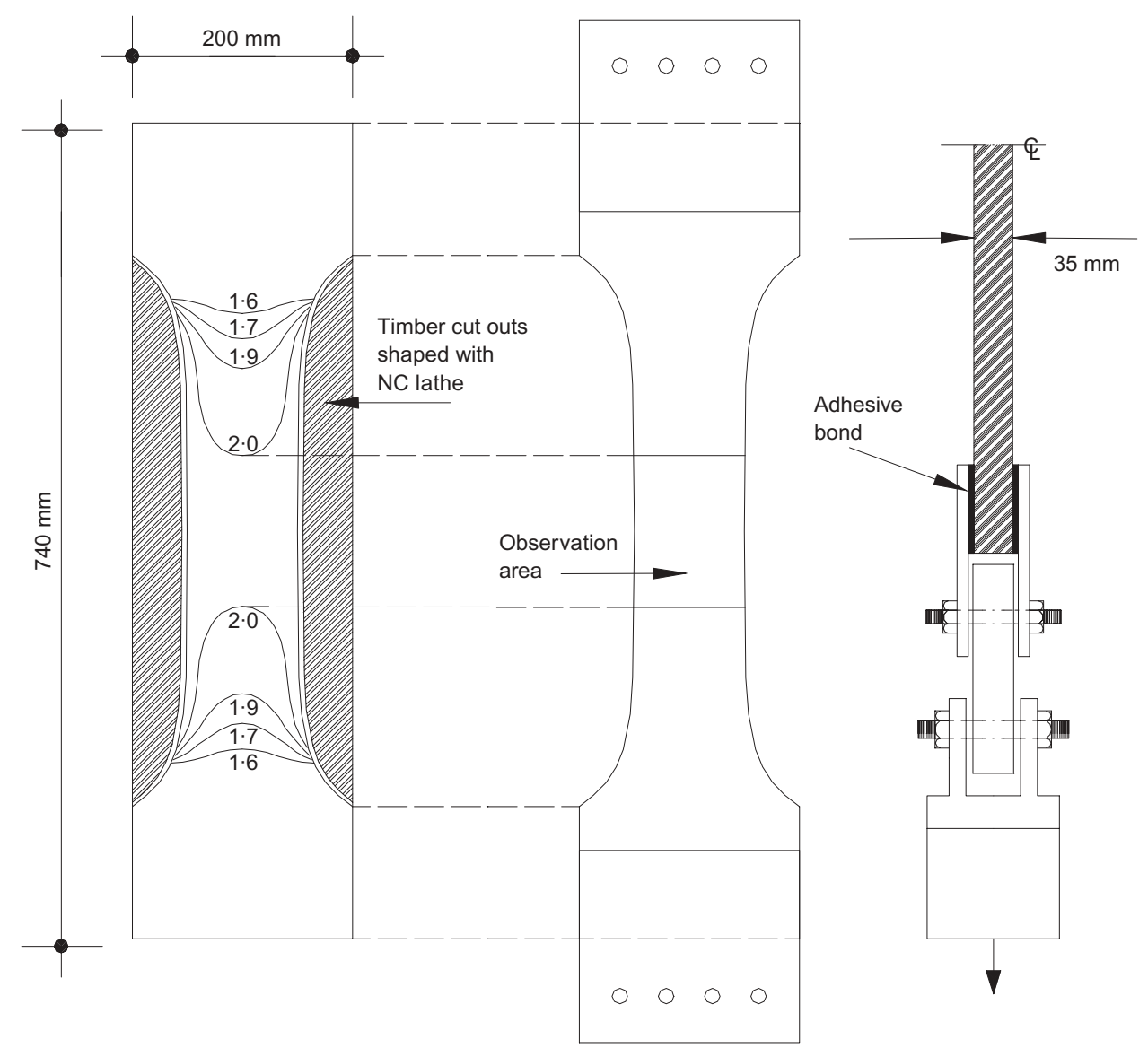

(a)

(b)

(c)

Fig. 4. Special tensile specimen geometry, showing (a) contours of tensile stress under a unit external tension, (b) the observation area with a uniform and well-defined tension field and (c) the load application arrangement

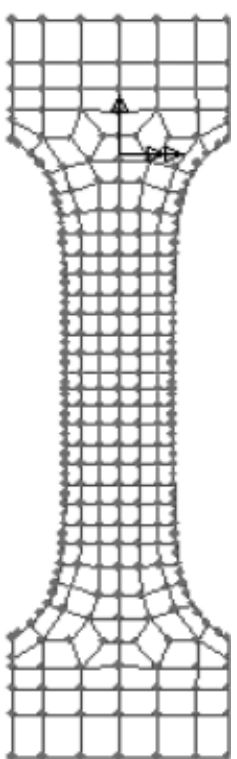

(a)

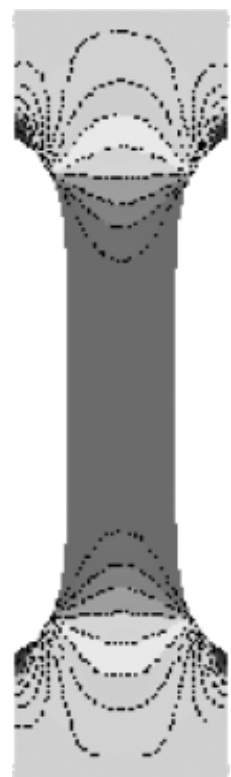

(b)

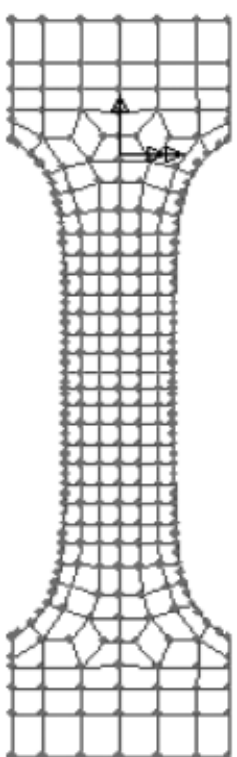

(a)

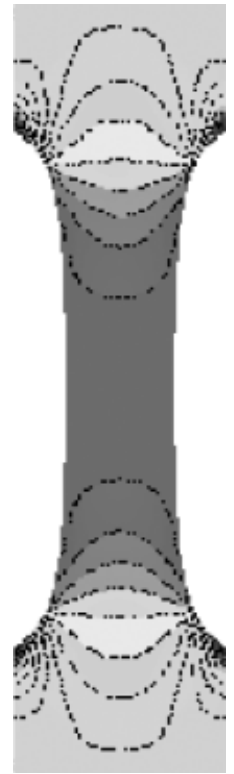

(b)
Fig. 5. Special tensile geometry, showing (a) surface domains to which a $4 \times 4$ mesh was applied and (b) contours of tensile stress under a unit external tension. The stress levels may be judged by comparing the four contours on either side of the horizontal axis of symmetry with the labelled contours in Fig. 4(a)
Fig. 6. Modified tensile geometry, showing (a) surface domains to which a $4 \times 4$ mesh was applied and (b) a smaller central area of tensile stress under a unit external tension. The stress levels may be judged by comparing the four contours on either side of the axis of symmetry with the labelled contours in Fig. 4(a)

Magazine of Concrete Research, 2005, 57, No. 8 


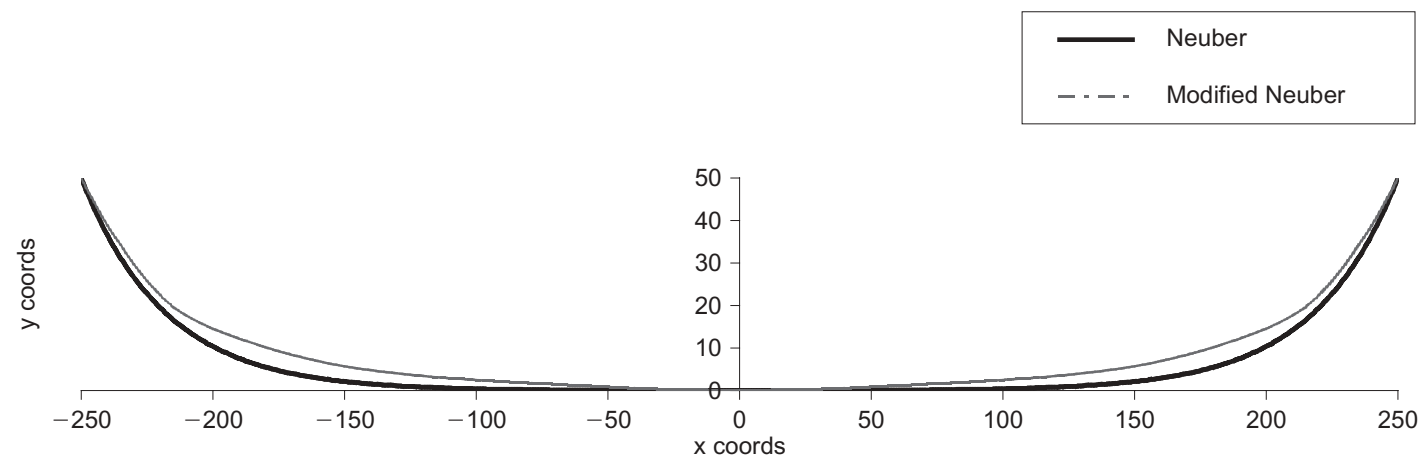

Fig. 7. Comparison of Neuber and modified Neuber splines

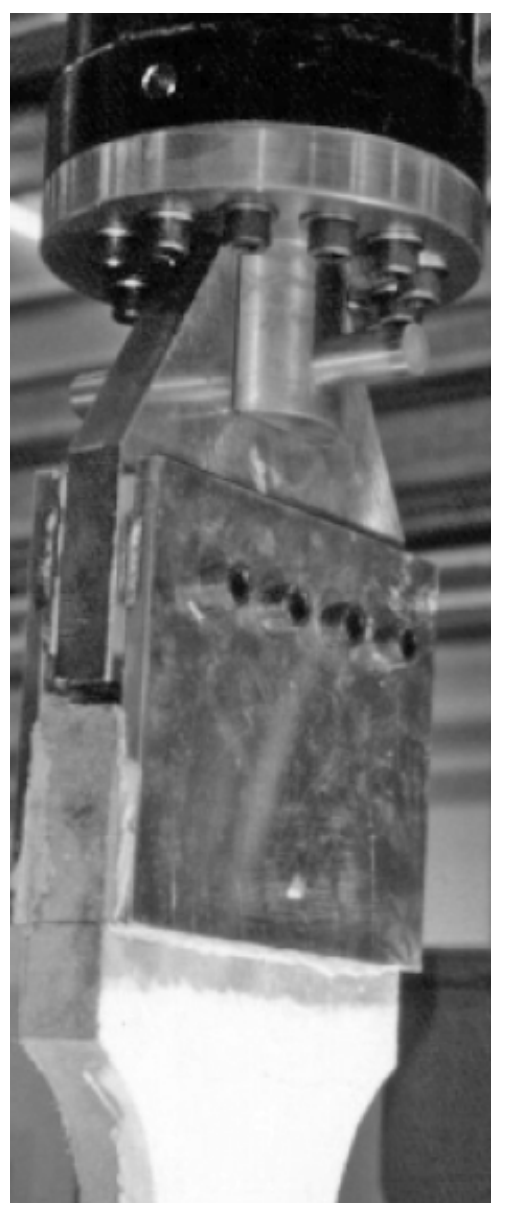

Fig. 8. Bonded pinned plates

These plates were then pinned to a top plate which was attached to a coupling with a pin. This pin passes through a floating (self-aligning) bearing (set in the top plate) to allow rotation of the specimen.

\section{Specimen alignment}

It is extremely difficult if not impossible to obtain a uniform state of stress in uniaxial testing of concrete even after ensuring that the test set-up is perfectly aligned at the beginning in order not to introduce effects due to bending. To ensure this, the alignment of the top and bottom couplings were checked (Fig. 4) and a purpose-built steel jig was used to bond the steel plates to the CARDIFRC ${ }^{\mathbb{B}}$ tensile specimen, thereby ensuring that the plates and specimen are in perfect alignment. The problem of misalignment arises during testing. In the early stages of the test when there were no or very few distributed microcracks there was no evidence of in- and out-of-plane bending. The linear variable displacement transducers (LVDTs) on the front and back faces of the specimen registered almost identical readings (Fig. 9). However, as the load was increased and a localised crack formed in one edge and began to propagate towards the opposite edge, bending was introduced into the specimen. This is evident from the LVDT readings (Fig. 9). The readings registered by the LVDTs along the centre line of the specimen on its front and back surfaces however, seem to be unaffected by bending and are used as the nominal values below.

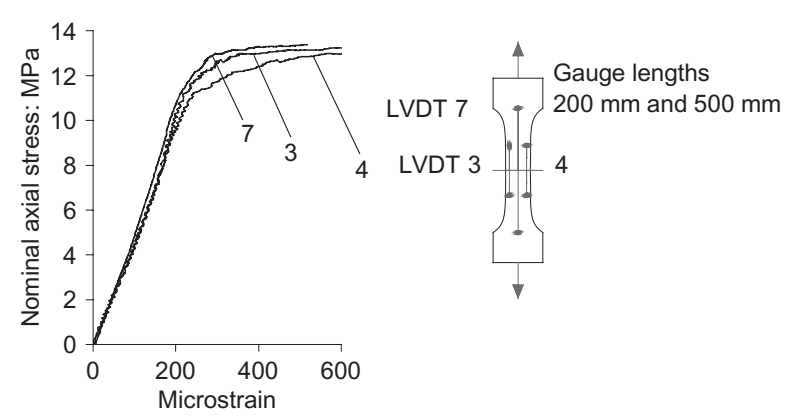

(a)
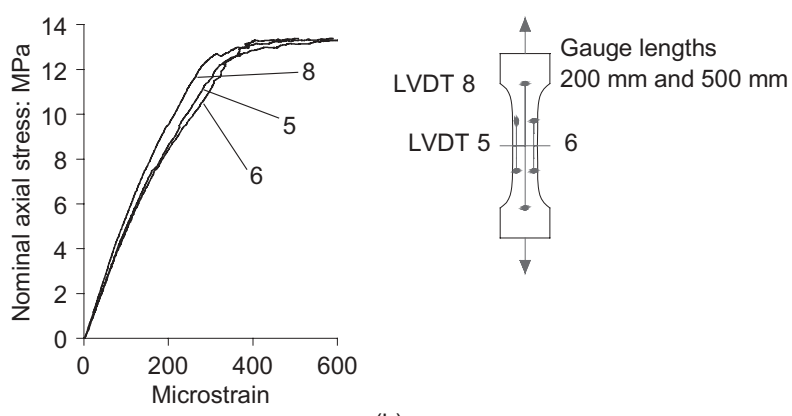

(b)

Fig. 9: (a) Pre-peak stress-microstrain readings for (a) observation face and (b) rear face 


\section{Specimen preparation and testing}

The Neuber and modified Neuber geometries were realised by feeding the exact co-ordinates into a numerically controlled lathe which produces timber cutouts. The latter were positioned in a rectangular steel mould, as shown in Fig. 4. The mould was then filled with the test CARDIFRC ${ }^{\circledR}$ mix and compacted on a non-magnetic vibrating table at $50 \mathrm{~Hz}$. The middle third of the flat surfaces of the specimen was coated with brittle whitewash. The specimen was loaded gradually in tension through the loading arrangement shown in Fig. 4 and its coated surfaces were scanned by the CCD camera for evidence of microcracks. As the length of microcracks is approximately equal to the maximum size of quartz sand used in the mix, a CCD camera coupled with a high magnification optical lens $(\times 60)$ is needed for this purpose. The CCD camera was mounted on a frame that enabled it to be moved both horizontally and vertically. The camera scanned the area of uniform stress for microcracks under increasing tensile loading. This process was continued until the microcracks localised into macrocrack(s) in the eventual fracture plane, namely until the peak load was reached. The test was controlled by a feedback signal from two control LVDTs, one on each face of the specimen (Fig. 10). The length of the control LVDTs is dictated by the desire to capture the fracture process zone (FPZ) on the one hand, and to avoid snapback behaviour on the other. Initially, therefore a control gauge length of $200 \mathrm{~mm}$ was chosen. However, it was found to be insufficient because the FPZ did not always form within this length owing to the large uniform stress region in the specimen. The control gauge length was therefore increased to $500 \mathrm{~mm}$ to cover the entire transition spline region. No snapback behaviour was observed in any of the tests. In addition to the two control LVDTs, four shorter LVDTs, two on each face of the specimen and on either side of the control LVDT, were also used to record the elongation of the specimen during loading. The control LVDTs were positioned

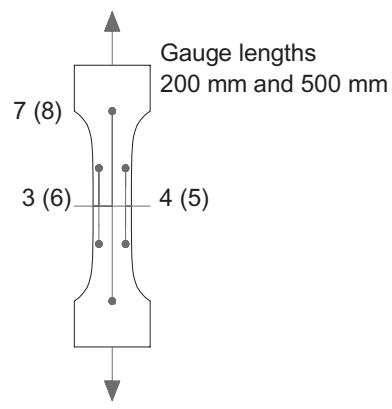

Fig. 10. Arrangement used for LVDTs mounted on the specimens. The LVDTs are mounted $15 \mathrm{~mm}$ in from the edges of the specimens or along the centre line. The first number denotes the LVDTs mounted on the observation face and the number in brackets denotes those mounted on the rear face along the centre line of the specimen so that they were nearly along the neutral axis when the specimen bent owing to the formation and growth of a localised crack from one of its edges. The readings of the control LVDTs were therefore practically unaffected by bending, whereas the readings of the shorter four LVDTs were affected by it.

\section{Results}

The novel test specimen profile proved to be very effective in providing a specific area of uniform tensile stress to facilitate the observation of crack evolution without inducing a bias into the location of crack initiation, although it was not possible to observe microcrack nucleation even at the high magnification used. The tests confirmed that the FPZ is not due to a dominant crack but due to many energy dissipation mechanisms, such as crack branching, crack coalescence, multiple/ parallel cracking, etc. (Fig. 11).

From the limited number of successful tests, the data recorded by the LVDTs that were practically unaffected by the specimen bending have been fitted with polynomials to describe the complete tensile response of CARDIFRC $^{\circledR}$ (Fig. 12). These approximate polynomials are practically indistinguishable from the test data, so that the experimental data cannot be seen on the scale of the figure. As is common with tension softening materials, the pre-peak response is described in terms of axial strain, whereas the post-peak response is described in terms of the overall elongation of the specimen over the gauge length. This elongation can be regarded as the average opening displacement of the localised crack along the failure plane.

The elastic region $(0 \leqslant \varepsilon<200 \mu$ strain $)$ is described by

$$
\sigma=0 \cdot 046 \varepsilon
$$

giving the Young's modulus value of $46 \mathrm{GPa}$. The strain hardening region $(200<\varepsilon<600 \mu$ strain $)$ is described by

$$
\begin{aligned}
\sigma= & -4.34 \times 10^{-10} \varepsilon^{4}+8.32 \times 10^{-7} \varepsilon^{3} \\
& -6.03 \times 10^{-4} \varepsilon^{2}+0.20 \varepsilon-12.62
\end{aligned}
$$

The tension softening region is described by the following relation between the residual stress carrying capacity and crack mouth opening, $w$.

$$
\begin{aligned}
\sigma= & 0.003 w^{7}-0.08 w^{6}+0 \cdot 82 w^{5}-4.420 w^{4} \\
& +12 \cdot 80 w^{3}-18 \cdot 11 w^{2}+5.73 w+12.89
\end{aligned}
$$

Note that equation (9) is valid for $0 \leqslant w \leqslant 6.5 \mathrm{~mm}$, where the upper limit is equal to one-half the length of the longest fibre. It is customary in the description of fibre-reinforced cementitious composites to regard the maximum crack mouth opening to be the one when the

Magazine of Concrete Research, 2005, 57, No. 8 


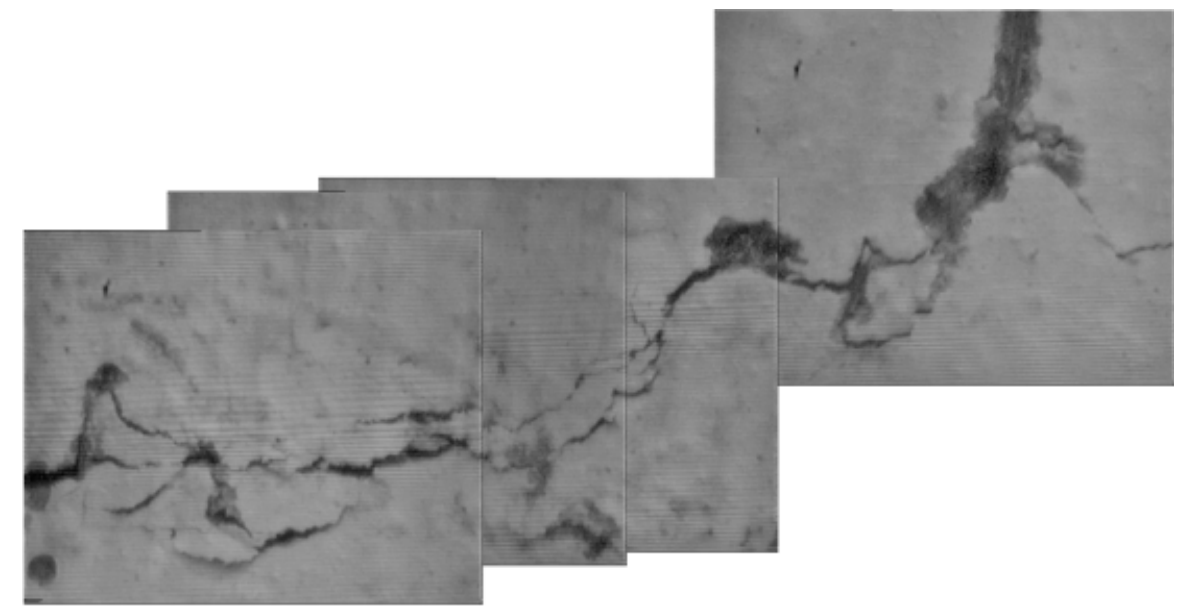

Fig. 11. Micro- and macrocracking observed using CCD camera

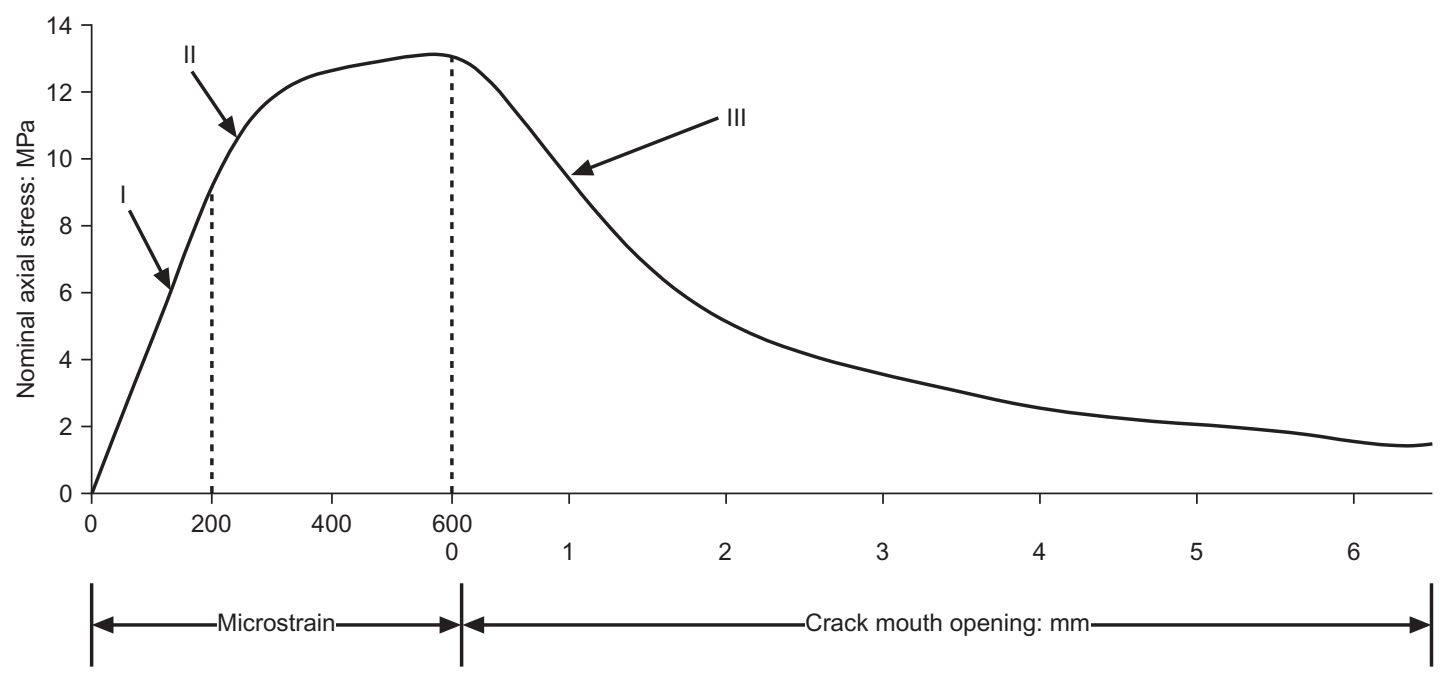

Fig. 12. Complete pre- and post-peak tensile curve for CARDIFRC $C^{\circledR}$ as described by equations (7)-(9)

longest fibre used in the composite is pulled out, assuming it to be embedded to equal depth on either side of a crack. From equation (9) the specific fracture energy $G_{\mathrm{F}}$ can be calculated

$$
G_{\mathrm{F}}=\int_{0}^{w_{\mathrm{c}}} \sigma(w) \mathrm{d} w
$$

where $w_{\mathrm{c}}=6.5 \mathrm{~mm}$.

After the initiation of matrix cracks at the termination of the elastic stage, further microcracks are formed. The density of these microcracks is small in the beginning so that the actual stiffness is reduced at a slow rate with increasing tensile stress. However, at a strain level of about 300 microstrain the density of microcracks increases rapidly with a further increase in tensile stress and reaches a saturation level at a strain level of about 600 microstrain. This rapid increase in the density of the microcracks towards the saturation level was noticeable as 'ripples' on the observation face, which was coated with a brittle whitewash. At this level of stress, some of the microcracks lying in the eventual fracture plane coalesce to form a macrocrack. Initially, this macrocrack forms on one of the faces (Fig. 13(a)) and propagates through the thickness (Fig. 13(b)). This results in a plateau in the stress-strain plot near the peak load (Fig. 12) since the specimen is still able to sustain the full load via the uncracked thickness. Once the crack has propagated through the thickness of the specimen the stress decreases. After the peak load, there is a gradual decrease in the stress indicating that the cracks are fragmented at the peak load. This is due to unbroken ligaments where the cracks have not linked up. This confirms the assumption made by Wang and Karihaloo $^{12}$ that a through crack does not form at the peak load but on the descending tension softening branch.

The tests showed only small differences in the mechanical properties between the two types of mix (CARDIFRC $^{\circledR}$ mix Type I and Type II) and the specific fracture energy values were in excellent agreement with 


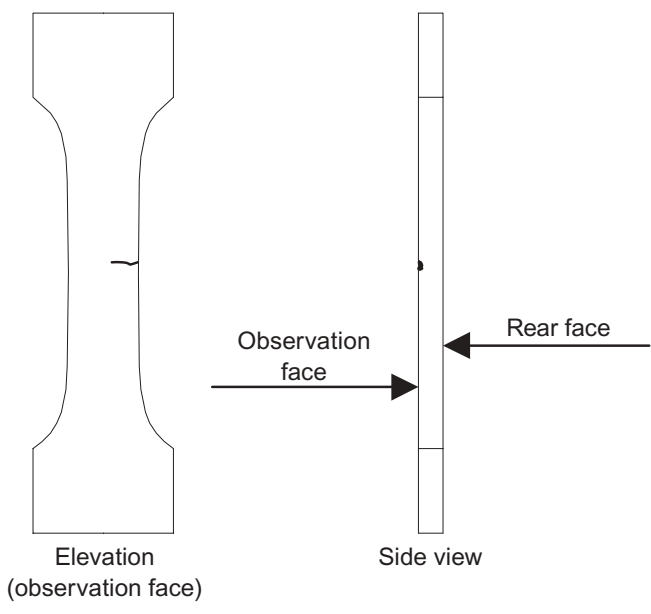

(a)

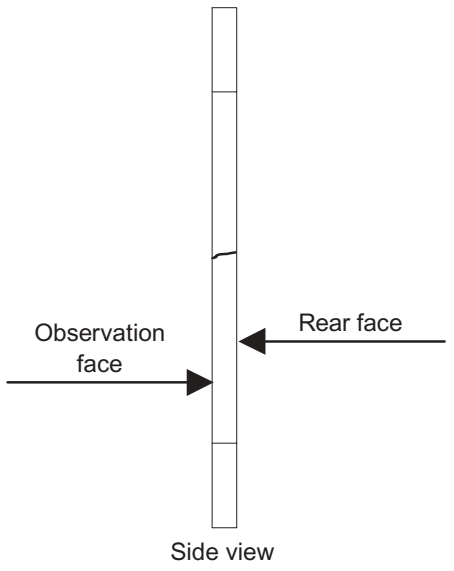

(b)

Fig. 13. (a) shows the observation face and side view of the Neuber spline. Note that the small crack is only visible on the observation face (this is where the stress-strain curve starts to plateau (Fig. 10), and (b) shows that the crack has propagated through the thickness of the specimen (this is the end of the plateau observed in the stress-strain curve)

those found by indirect flexural tests (see below). The specific fracture energy $G_{\mathrm{F}}$ (equation (10)) was found to be in the region of 17000 to $20500 \mathrm{~N} / \mathrm{m}$. The uniaxial tensile strength was between 12 and $13 \cdot 5 \mathrm{MPa}$. The experimental results are for the nominal axial stress and therefore the uniaxial tensile strength $\left(f_{\mathrm{t}}\right)$ is on the conservative side since the effect of bending is not included. The toughness results, however, are not affected by bending as they are determined from loaddisplacement data recorded along the centre line of the specimen which nearly coincides with its neutral axis when it bends after the formation of a through-thethickness macrocrack along one of its edges.

\section{Constitutive relations}

The constitutive relations (presented in Part I of this paper) relate the mechanical response parameters to the mix and fibre parameters. The constitutive description aims at identifying the mechanisms responsible for observed mechanical behaviour and at relating the mix variables (water to binder ratio, $w / b$, maximum size of coarse aggregate, $g$, volume fraction of aggregate $V_{\mathrm{a}}$, surfactant to water ratio $s p / w$, fibre length, $L$, fibre diameter, $d$, and fibre volume fraction, $V_{\mathrm{f}}$ ) to the measurable mechanical properties (modulus of elasticity, $E$, tensile strength, $f_{\mathrm{t}}$, compressive strength, $f_{\mathrm{c}}$, and the energy absorption capacity per unit crack area, $G_{\mathrm{F}}$ ). The accuracy of these micromechanical relations is judged by comparing the theoretical predictions with the experimental results from the uniaxial tension tests described above.

\section{Modulus of elasticity}

To calculate the modulus of elasticity for CARDIFRC $^{\circledR}$, the following equation ${ }^{13}$ is applied twice

$$
E=E_{m}[n+\Theta+V \Theta(n-1)] /[n+\Theta-V(n-1)]
$$

First, it is applied to a two-phase system in which the continuous phase is the cement-silica binder paste and the discrete phase is the fine aggregate. For the elastic modulus of the binder $\left(E_{\mathrm{b}}\right), E_{m}$ in equation (11) is the elastic modulus of the paste $\left(E_{\mathrm{p}}\right)$ (assumed to be $30 \mathrm{GPa}$ ) and $n$ is the ratio of the modulus of elasticity of the fine aggregate $\left(E_{\mathrm{a}}\right)$ (assumed to be $70 \mathrm{GPa}$ ), to $E_{\mathrm{p}} . V$ is the volume fraction of aggregate and $\Theta$ can be determined from the relations given in Ref. 13. These relations depend on $E_{\mathrm{a}}$ and the aspect ratio of the fine aggregate particles which is equal to 1 for the nearly spherical quartz sand particles used in CARDIFRC ${ }^{\circledR}$.

Equation (11) is applied again, this time the cementmicrosilica-quartz sand mortar is the continuous phase and the fibres the discrete phase. The values of $n, V, E_{m}$ and $\Theta$ are different in this step. $E_{m}$ is the elastic modulus of the binder $\left(E_{\mathrm{b}}\right)$ obtained in the previous step and $n$ is the ratio of the modulus of elasticity of the steel fibres $\left(E_{\mathrm{f}}\right)$ (assumed to be $210 \mathrm{GPa}$ ), to $E_{\mathrm{b}}$. $V$ is the volume fraction of fibres and $\Theta$ depends on $V$ and the needle-like shape of the fibres. ${ }^{13}$

Applying the above two-step procedure to CARDIFRC $^{\mathbb{R}}$ mix Types I and II with $L=6 \mathrm{~mm}$ (the short fibres have a greater effect in the pre-peak region ${ }^{14-16}$ ), $V_{\mathrm{f}}=0.06, V_{\mathrm{a}}=0.36$ for mix Type I and $V_{\mathrm{a}}=0.45$ for mix Type II, and maximum aggregate size of $0.6 \mathrm{~mm}$ for mix Type I and $2 \mathrm{~mm}$ for mix Type II, gives $E=45 \mathrm{GPa}$ for mix Type I and $48 \mathrm{GPa}$ for mix Type II. The predicted value for mix Type I is in excellent agreement with the value measured in the uniaxial tension tests, namely $46 \mathrm{GPa}$ (see equation (7)). Recently, a higher value has been measured (55 GPa) (D. Nicolaides, personal comm.) on mixes with a slightly higher $s p / w$ of $0 \cdot 18$ (compared with $0 \cdot 15$ ) for mix Type

Magazine of Concrete Research, 2005, 57, No. 8 
I and $0 \cdot 40$ (compared with $0 \cdot 37$ ) for mix Type II. This higher $s p / w$ is likely to have produced a denser and therefore a stiffer binder such that $E_{\mathrm{p}}$ in step 1 above would exceed the assumed value of $30 \mathrm{GPa}$.

\section{Uniaxial tensile strength}

It is assumed that the initial microcracks do not propagate until the attainment of $f_{\mathrm{t}}$ but are supplemented by newly formed cracks. This is the well-known multiple cracking behaviour in DSP (densified systems containing homogeneously arranged ultrafine particles) type mixes. ${ }^{16,17}$ At the peak load when the cracks are still unconnected the load is carried by both the unbroken material ligaments and the fibres that exert closure pressure on the cracks between these ligaments.

The contribution of the unbroken ligaments to $f_{\mathrm{t}}$ depends upon the unreinforced matrix and the volume fraction of fibres

$$
f_{\mathrm{t}}^{*}=\frac{K_{\mathrm{Ic}, \mathrm{m}}}{\sqrt{\pi a_{0}}}\left(1-V_{\mathrm{f}}\right)
$$

where $K_{\mathrm{Ic}, \mathrm{m}}$ is the fracture toughness of the matrix (see equation (5) in Part I). The half-length of each crack segment in the array at peak load is given by

$$
a_{0}=1 \cdot 5 g+e / 2
$$

where $g$ is the maximum aggregate size and $e$ is the edge-to-edge spacing between the spherical aggregate particles given by

$$
e=g_{\mathrm{av}}\left(V_{\mathrm{a}}^{-1 / 3}-1\right)
$$

where $g_{\mathrm{av}}$ is the average size of aggregates in the mix.

The contribution of the bridging action of fibres on the cracks depends on several factors ${ }^{16,17}$

$$
f_{\mathrm{t}}^{* *}=\frac{h}{4} L V_{\mathrm{f}} \alpha K_{\mathrm{Ic}, \mathrm{m}} \sqrt{\frac{1}{d} \frac{E_{\mathrm{f}}}{E_{\mathrm{b}}}}
$$

$\alpha$ is a dimensioned parameter which is controlled by $h$. The latter is the so-called snubbing coefficient which allows for the dowel action of fibres. ${ }^{18}$

$$
h=\frac{2}{4+f^{2}}\left(\mathrm{e}^{f \pi / 2}+1\right)
$$

where $f$ is the coefficient of friction between the fibre and matrix.

Thus, the tensile strength of the mix is

$$
f_{\mathrm{t}}^{\prime}=\frac{K_{\mathrm{Ic}, \mathrm{m}}}{\sqrt{\pi a_{\mathrm{o}}}}\left(1-V_{\mathrm{f}}\right)+\frac{h}{4} L V_{\mathrm{f}} \alpha K_{\mathrm{Ic}, \mathrm{m}} \sqrt{\frac{E_{\mathrm{f}}}{d E_{\mathrm{b}}}}
$$

The effective fracture toughness $K_{\text {Ic, } m}$ of the CARDIFRC $^{\circledR}$ matrix without fibres depends on the operating toughening mechanisms (induced by the presence of fine aggregates). Thus, the toughening induced by crack deflection (equation (19)), distributed interfacial cracking (equation (20)), and bridging and trapping (equation (21)) over and above the cement-microsilica binder toughness $K_{\mathrm{Ic}, \mathrm{p}}$ is given by ${ }^{19,20}$

$$
\begin{gathered}
\frac{K_{\mathrm{Ic}, \mathrm{m}}}{K_{\mathrm{Ic}, \mathrm{p}}}=\sqrt{1 \cdot 0+0 \cdot 87 V_{\mathrm{a}}} \\
\frac{K_{\mathrm{Ic}, \mathrm{m}}}{K_{\mathrm{Ic}, \mathrm{p}}}=\sqrt{\frac{1}{1-\left(\pi^{2} / 16\right) V_{\mathrm{a}}\left(1-v^{2}\right)}} \\
\frac{K_{\mathrm{Ic}, \mathrm{m}}}{K_{\mathrm{Ic}, \mathrm{p}}}=\sqrt{\chi^{2}+\frac{E_{\mathrm{b}}^{\prime}}{E_{\mathrm{b}}} \frac{\pi f_{\mathrm{t}, \mathrm{a}}^{2} g_{\mathrm{av}} V_{\mathrm{a}}\left(1-\sqrt{\left.V_{\mathrm{a}}\right)}\left(V_{\mathrm{a}}-V_{\mathrm{a}}^{2}\right)\right.}{2\left(K_{\mathrm{Ic}, \mathrm{m}}\right)^{2}}}
\end{gathered}
$$

where

$$
\chi=\left\{1-\frac{\left(1-V_{\mathrm{a}}\right) \pi / 4}{\ln \left\{\left[1+\cos \left(\pi V_{\mathrm{a}} / 2\right)\right] /\left[\sin \left(\pi V_{\mathrm{a}} / 2\right)\right]\right\}}\right\}^{-1}
$$

$f_{\mathrm{t}, \mathrm{a}}$, the uniaxial tensile strength of the aggregate, is assumed to be $10 \mathrm{MPa}$, and $v$, Poisson's ratio of the hardened matrix, is assumed to be $0 \cdot 25 . E_{\mathrm{b}}^{\prime}$ is the modulus of elasticity of the binder (i.e. without fibres) with interfacial cracks and $E_{\mathrm{b}}$ is that of the binder without interfacial cracks. $E_{\mathrm{b}}^{\prime}$ can be determined from Ref. 18.

$$
\frac{E_{\mathrm{b}}^{\prime}}{E_{\mathrm{b}}}=1-\frac{\pi^{2}}{16}\left(1-v^{2}\right) V_{\mathrm{a}}
$$

The above formulae are now used to determine the theoretical uniaxial tensile strength for CARDIFRC ${ }^{\circledR}$ mix Types I and II. The differences in $K_{\text {Ic,m }}$ (equation (5), Part I) between mix Types I and II are due to differences in the volume fraction of fine aggregate and its maximum size which give rise to different operating toughening mechanisms. Thus in mix Type I because of the smaller maximum size sand $(g=0.6 \mathrm{~mm})$ the crack trapping mechanism would be almost absent, whereas this mechanism would play a role in mix Type II with the coarser sand $(g=2 \mathrm{~mm})$. Lange-Kornbak ${ }^{17}$ states that when any crack trapping is disregarded the empirical constant $\alpha$ (appearing in equation (18)) equals $932 \mathrm{~m}^{-1}$ and when full crack trapping is present $\alpha$ equals $342 \mathrm{~m}^{-1}$. The empirical constant $\alpha$ is therefore assumed to be $932 \mathrm{~m}^{-1}$ for mix I and $700 \mathrm{~m}^{-1}$ for mix II. It is known that up until the maximum load it is the short $(6 \mathrm{~mm})$ fibres that contribute to a higher tensile strength, therefore $L$ in equation (18) is $6 \mathrm{~mm}$. The coefficient of friction in formula (17), $f$, between the fibre and the matrix is assumed to be 0.5 for both mix Types I and II. For mix Type I with $V_{\mathrm{a}}=0.36$ and $K_{\mathrm{Ic}, \mathrm{m}}=0.99 \mathrm{MPa} \mathrm{m}^{1 / 2}$, (equation (5), Part I) $f_{\mathrm{t}}$ is evaluated to be equal to $12 \cdot 2 \mathrm{MPa}$; for mix Type II with $V_{\mathrm{a}}=0.45$ and $K_{\mathrm{Ic}, \mathrm{m}}=1.19 \mathrm{MPa} \mathrm{m}^{1 / 2}, f_{\mathrm{t}}$ works out to be equal to $13 \mathrm{MPa}$. These theoretical results are in good agreement with the values measured in uniaxial tension above, namely $12-13 \cdot 5 \mathrm{MPa}$. 


\section{Specific fracture energy}

The specific fracture energy $\left(G_{\mathrm{F}}\right)$ is given by ${ }^{17}$

$$
G_{\mathrm{F}}=\int_{w=0}^{L / 2} \sigma(w) \mathrm{d} w \approx \frac{h}{24} L^{2} V_{\mathrm{f}} \alpha K_{\mathrm{Ic}, \mathrm{m}} \sqrt{\frac{1}{d} \frac{E_{\mathrm{f}}}{E_{\mathrm{b}}}}
$$

The maximum fibre length is $13 \mathrm{~mm}$ since it is the long fibres that contribute the most to the specific fracture energy by bridging the cracks in the softening range and increasing the ductility. ${ }^{14,17}$ The values for $V_{\mathrm{f}}, f, \alpha, K_{\mathrm{Ic}, \mathrm{m}}, E_{\mathrm{f}}$ and $E_{\mathrm{b}}$ are identical to those used to determine $f_{\mathrm{t}}$ above. The formula predicts the specific fracture energy for mix I to be $13247 \mathrm{~N} / \mathrm{m}$ and that for mix II to be $18635 \mathrm{~N} / \mathrm{m}$. The experimental values determined by uniaxial tension tests were $17000 \mathrm{~N} / \mathrm{m}$ for $\operatorname{mix} I$ and $20500 \mathrm{~N} / \mathrm{m}$ for mix II. The theoretical predictions are somewhat lower than the measured values because of the assumption that the load-carrying capacity is exhausted when the crack opening reaches the value $L / 2=6.5 \mathrm{~mm}$, whereas in reality the composite continues to carry load beyond this value of crack opening (see Fig. 10). The theory does however predict that mix II is somewhat more ductile than mix I; this is because mix II has a higher volume fraction of long fibres $(1 \cdot 5 \%)$ than mix I (1\%).

\section{Compressive strength}

The crack pattern observed under uniaxial tension is much the same as under uniaxial compression. ${ }^{17}$ In fact, cracks form under uniaxial compression because the local tensile stress reaches the tensile strength of the concrete. When the stress intensity factor $K_{\mathrm{Ic}}(u)$ at a crack tip equals the fracture toughness of the matrix $\left(K_{\mathrm{Ic}, \mathrm{m}}\right)$ it will propagate. $\mathrm{Li}^{21}$ proposed the so-called wing crack model for failure under uniaxial compression (Fig. 14). His calculations show that

$$
K_{\mathrm{I} c}(u)=\frac{\sqrt{2} c \tau}{\sqrt{b \sin (\pi u / b)}}
$$

If it is assumed that the inclined cracks form at $45^{\circ}$ to the applied uniaxial compression stress ( $\beta$ in Fig. $14)$, then the resolved shear stress on these cracks is

$$
\tau=\frac{\sigma}{\sqrt{2}}(1-\mu)-\tau_{\mathrm{B}}
$$

where $\mu$ is the coefficient of friction between crack faces, $b$ is the centre to centre distance between cracks (Fig. 14) given by $b=g_{\text {av }}+e$, and $e$ is given by equation (14). The second term on the right-hand side of equation (26) is the contribution from the closure pressure exerted by the fibres which is approximately equal to that given by equation (16).

The tensile strength of the CARDIFRC ${ }^{\circledR}$ matrix alone is related to its fracture toughness as follows (cf. equation (12))

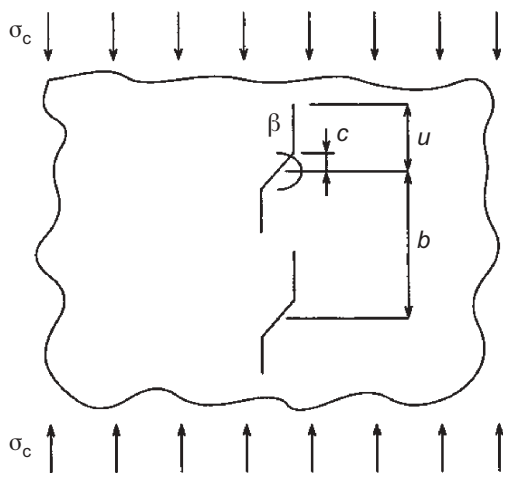

Fig. 14. Wing crack model (After Ref. 21)

$$
f_{\mathrm{t}, \mathrm{b}}=\frac{K_{\mathrm{Ic}, \mathrm{m}}}{\sqrt{\pi a_{\mathrm{o}}}}
$$

where $f_{\mathrm{t}, \mathrm{b}}$ is the tensile strength of the matrix and $a_{\mathrm{o}}$ is the half crack length at $f_{\mathrm{t}, \mathrm{b}}$. So, cracks will propagate in the matrix when $K_{\mathrm{Ic}}(u)$ in equation (25) attains the matrix fracture toughness $K_{\mathrm{Ic}, \mathrm{m}}$ which, with the use of equation (27), gives

$$
f_{\mathrm{t}, \mathrm{b}} \sqrt{\pi a_{\mathrm{o}}}=\frac{\sqrt{2} c \tau}{\sqrt{b \sin (\pi u / b)}}
$$

The corresponding value of applied compressive stress $\sigma_{\mathrm{c}}$ is the compressive strength of CARDIFRC ${ }^{\circledR}$, $f_{\mathrm{c}}$. Rearranging equation (28), and substituting for $\tau$ (equation (26)), and denoting the corresponding value of $\sigma_{\mathrm{c}}=f_{\mathrm{c}}$, gives

$$
f_{\mathrm{t}, \mathrm{b}} \sqrt{\pi a_{\mathrm{o}}}=\frac{\sqrt{2} c \frac{1}{\sqrt{2}}\left[f_{\mathrm{c}}(1-\mu)-\sqrt{2} \tau_{\mathrm{B}}\right]}{\sqrt{b \sin (\pi u / b)}}
$$

or,

$$
f_{\mathrm{c}}=\frac{\frac{f_{\mathrm{t}, \mathrm{b}} \sqrt{\pi a_{\mathrm{o}} b \sin (\pi u / b)}}{c}+\sqrt{2} \tau_{\mathrm{B}}}{1-\mu}
$$

in which $u$ is still unknown. However, when $\sigma_{\mathrm{c}}=f_{\mathrm{c}}$, $u \approx b / 2$ (Fig. 14) giving

$$
f_{\mathrm{c}}=\frac{f_{\mathrm{t}, \mathrm{b}} \sqrt{\frac{\pi a_{\mathrm{o}} b}{c^{2}}}+\sqrt{2} \tau_{\mathrm{B}}}{1-\mu}
$$

This formula will now be used to predict the $f_{\mathrm{c}}$ of CARDIFRC $^{\circledR}$.

The coefficient of friction between the crack faces, $\mu$, is assumed to be 0.7 for mix I and 0.72 for mix II. The higher value of $\mu$ for mix II is predicated by the larger maximum aggregate size quartz sand used in this mix. The theoretical values for $f_{\mathrm{c}}$ are $219 \mathrm{MPa}$ for mix I and $184 \mathrm{MPa}$ for mix II, which are in good

Magazine of Concrete Research, 2005, 57, No. 8 
agreement with the experimental values 207 and $185 \mathrm{MPa}$, respectively.

\section{Conclusions}

The uniaxial tension test gives a good overall description of the load-deformation diagram of CARDIFRC $^{\circledR}$ until complete failure despite the bending induced in the specimen due to asymmetric crack formation and growth. For this it was necessary to use several LVDTs on each face of the specimen. Tests showed that the mixture has a smaller strain hardening region than expected. ${ }^{6-8}$ This is attributed to the reduced number of microcracks formed in the material prior to the formation of a macrocrack.

The micromechanical relations describing the constitutive behaviour of CARDIFRC ${ }^{\circledR}$ predict the tensile strength $f_{\mathrm{t}}$, the compressive strength $f_{\mathrm{c}}$, the toughness of the material $G_{\mathrm{F}}$ and the modulus of elasticity $E$, as a function of the mix and fibre parameters. Most importantly, they allow the workability of the mix (without fibres) to be included indirectly through the fracture toughness of the brittle matrix. This was achieved by first expressing the latter as a function of the mix variables $\left(V_{\mathrm{a}}, w / b, s p / w\right.$ and $\left.g\right)$ for a given workability. However, due to limitations of the cone penetration test, it was not possible to test the matrix with the same workability as that of the CARDIFRC ${ }^{\mathbb{R}}$ mixes. Therefore, the values of $K_{\mathrm{Ic}, \mathrm{m}}$ for these mixes are not known exactly. An inaccuracy in the assumed values would explain some of the discrepancies observed between theoretical and measured values.

\section{Acknowledgement}

This work is supported by the UK EPSRC grant GR/R11339.

\section{References}

1. VAn Mier J. G. M. Fracture Processes of Concrete. CRC Press, Boca Raton, FL, USA, 1997.

2. Karihaloo B. L. and WANG J. Micromechanics of fiber-reinforced cementitious composites. Journal of Advanced Engineering Materials, 2000, 2, No. 11, 726-732.

3. KaRiHaloo B. L. and WANG J. Micromechanical modelling of strain hardening and tension softening in cementitious composites. Computational Mechanics, 1997, 19, No. 6, 453-462.

4. Karihaloo B. L., Wang J. and Grzybowski M. Doubly periodic arrays of bridged cracks and short fibre-reinforced cementitious composites. Journal of the Mechanics and Physics of Solids, 1996, 44, No. 10, 1565-1586.
5. Karihaloo B. L. and Wang J. J. Mechanics of fibre-reinforced cementitious composites. Computers \& Structures, 2000, 76, Nos. 1-3, 19-34.

6. Lange-Kornbak D. and Karihaloo B. L. Design of concrete mixes of minimum brittleness. Journal of Advanced CementBased Materials, 1996, 3, No. 2, 124-132.

7. Lange-Kornbak D. and Karihaloo B. L. Tension softening of short-fibre-reinforced cementitious composites. Journal of Cement and Concrete Composites, 1997, 19, No. 4, 315-329.

8. Lange-KornbaK D. and Karihaloo B. L. Design of fiberreinforced DSP mixes for minimum brittleness. Advanced Cement Based Materials, 1998, 7, No. 2, 89-101.

9. Van Vliet , M. R. A. Size Effect in Tensile Fracture of Concrete and Rock. PhD Thesis, Delft University of Technology, 2000 .

10. Neuber H. Der zugbeanspruchte flachstab mit optimalem querschnittsübergang. Forschung im Ingenieurwesen, 1969, 35, No. $1,29-30$.

11. Cattaneo S. and Rosati G. Effect of different boundary conditions in direct tensile tests: experimental results. Magazine of Concrete Research, 1999, 51, No. 5, 365-374.

12. Wang J. and Karihaloo B. L. Material instability in the tensile response of short-fibre-reinforced quasi-brittle composites. Archives of Mechanics, 2000, 52, Nos. 4-5, 839-855.

13. Karihaloo B. L \& Lange-KornbaK D. Optimisation techniques for the design of high-performance fibre-reinforced concrete. Structural and Multidisciplinary Optimisation, 2001, 21, No. 1, 32-39.

14. Sullivan A. P. The Effect of Hydro-thermal Curing at $90^{\circ} \mathrm{C}$ and the Use of $12 \mathrm{~mm}$ Steel Fibres on Reactive Powder Concrete. MSc Thesis, University of Wales, Cardiff, 1999.

15. Mobasher B., Stang H. and Shah S. P. Microcracking in fiber reinforced concrete. Cement and Concrete Research, 1990, 20, No. 5, 665-676.

16. Tuiptobroto P. and Hansen W. Tensile strain hardening and multiple cracking in high-performance cement-based composites containing discontinuous fibres, ACI Materials Journal, 1993, 90, No. 1, 16-25.

17. LANGE-KoRnBAK D. The Role of Brittleness in the Fracture of Plain and Reinforced Concrete. PhD Thesis, University of Sydney, 1997.

18. Li V. C., WANG Y. and BACKer S. A micromechanical model of tension-softening and bridging toughening of short random fiber reinforced brittle matrix composites, Journal of the Mechanics and Physics of Solids, 1991, 39, No. 5, 607-625.

19. Huang J. and Li V. C. A meso-mechanical model of the tensile behaviour of concrete. Part II: modelling of post-peak tension softening behaviour, Composites, 1989, 20, No. 5, 370-378.

20. LI V. C. and HuANG J. Crack trapping and bridging as toughening mechanisms in high strength concrete, In Proceedings of the International Conference on Micromechanics of Failure of Quasi-Brittle Materials, (ShaH S. P., Swartz S. P. and Wang M. L. (eds.)). Elsevier Applied Science, London, 1990, pp. 579-588.

21. LI, V. C. Postcrack scaling relations for fibre reinforced cementitious composites, Journal of Materials in Civil Engineering, 1992, 4, No. 1, 41-57.

Discussion contributions on this paper should reach the editor by 1 April 2006 